\title{
Beyond GDP: Lessons for Redefining Progress in Canadian Food System Policy
}

\author{
Naomi Robert* and Kent Mullinix \\ Institute for Sustainable Food Systems, Kwantlen Polytechnic University, Surrey, BC, Canada
}

Gross Domestic Product (GDP), while initially conceived to measure economic activity, is now the most widely used indicator for societal progress and wellbeing. Its contemporary (mis)use has been documented and discussed in 'Beyond GDP' research. This minireview brings a food systems lens to Beyond GDP research by providing an overview of the limitations of GDP as an indicator of wellbeing, and by illustrating examples of how these are embodied in Canadian food system policy. We offer a brief summary of some established and emerging areas of research dedicated to improving assessments of societal wellbeing in policy development. We highlight connections between Beyond GDP research and advocacy for food system policy reform and suggest that strengthening connections between the two areas of research and advocacy can help center societal wellbeing within food system policy research and development in Canada.

OPEN ACCESS

Edited by:

Myriam Durocher,

Carleton University, Canada

Reviewed by:

Voltaire Alvarado Peterson, University of Concepcion, Chile

Rod MacRae,

York University, Canada

*Correspondence:

Naomi Robert

naomi.robert@kpu.ca

Specialty section:

This article was submitted to

Science and Environmental

Communication,

a section of the journal

Frontiers in Communication

Received: 22 August 2021

Accepted: 20 December 2021

Published: 21 January 2022

Citation:

Robert N and Mullinix K (2022) Beyond GDP: Lessons for Redefining Progress

in Canadian Food System Policy.

Front. Commun. 6:762482.

doi: 10.3389/fcomm.2021.762482
Keywords: ecological economics, GDP, societal wellbeing, Canadian agri-food system, agriculture policy, food system policy

\section{INTRODUCTION}

Gross Domestic Product (GDP) is a measure of the total monetary value of all final goods and services within a jurisdiction, usually measured over a year. GDP is the most widely used governmental indicator for societal progress (Costanza et al., 2009; Raworth, 2017). The assumption underlying this application is that increasing economic production will increase societal wellbeing. So central is GDP to policy development, that the metric has been called "the world's most powerful number" (Fioramonti, 2013) and is used ubiquitously as both a policy objective and a metric to assess policy success across government domains.

Despite its contemporary (mis)use, GDP was not conceived as an indicator of wellbeing. The origins of contemporary GDP are often traced back to American economist Simon Kuznets, who developed a single measure of national income for the purpose of assessing the economic impact of, and recovery from, the Great Depression (Raworth, 2017). After the second world war, GDP was adopted by international financial institutions, notably the World Bank and the International Monetary Fund, as the standard for tracking economic activity with a single, convenient, aggregate statistic. The indicator evolved in the latter half of the 21 st century to become, by extension, a measure of societal progress and wellbeing (Stiglitz, 2020).

Ecological economics aims to embed human activity within its life-supporting ecosystems. Its objective is to advance ecologically sustainable societies that equitably share resources between humans, generations and non-human species (Costanza, 2008). An established body of ecological economic research documents the challenges of conflating economic activity with societal wellbeing (Stiglitz et al., 2009; Stiglitz et al., 2010; Washington, 2021). This work underscores how GDP, now used out of context, obscures important dimensions of wellbeing, incentivizes short-term profits over long-term prosperity, and skews our decision- 
making and policy development. Many have called for improved frameworks to move beyond GDP and ensure that our decisionmaking is informed by values such as ecological health, quality of life, equality, political voice etc. (Stiglitz et al., 2009; Giannetti et al., 2015; Raworth, 2017; Podlasly et al., 2020; Washington and Maloney, 2020).

This mini-review article brings a food systems lens to this body of work, referred to as 'Beyond GDP' literature. It provides an overview of the well-documented limitations of GDP as a guiding policy metric, and presents examples of how these are embodied within Canadian agriculture and food (agri-food) policy. It then provides a brief summary of some established and emerging research dedicated to moving beyond GDP with alternative metrics and policy paradigms. We conclude by suggesting opportunities to draw from Beyond GDP scholarship to advance research centering wellbeing in Canadian agriculture and food policy.

\section{DISCUSSION}

The food system is the network of people, activities and resources that provide communities with food. This includes farming and other forms of food provisioning, as well as food distribution, processing, retail, preparation and waste management. The food system is multifunctional. In other words, it is central to achieving multiple goals related to the wellbeing of society, including feeding people, sustaining human health, providing jobs and opportunities to create businesses, and supporting community economic development etc. Food system policy research in Canada often emphasizes that existing policy overlooks many of these important dimensions of human wellbeing for the purpose of economic growth in the agri-food sector (Andrée et al., 2018; Koc et al., 2008; MacRae, 1999; MacRae, 2011). Advocates for food system policy reform have expressed this critique in a number of ways. MacRae (1999) assessed that Canada "do[es] not have a food system, but an agriculture and agri-food industry" and that rather than nourish people, the goal of the Canadian food system is to grow a profitable, competitive agricultural industry. Others noted that the food system is not managed in the public interest (Food Secure Canada [FSC], 2015; Levkoe et al., 2017), or that food system policy should improve coordination to address policy gaps and contradictory outcomes (Food Secure Canada [FSC], 2015; Food Secure Canada [FSC], 2017). In all of these framings, we believe that calls for food system policy reform echo broader arguments in the Beyond GDP literature, notably that economic growth in-of-itself is insufficient to ensure wellbeing.

\section{Centering Growth in Canadian Agri-Food Policy}

The majority of Canadian food policy development has been undertaken by Agriculture and Agri-food Canada [AAFC] (formerly Agriculture Canada), and focuses on the agri-food sector $^{1}$ (MacRae, 1999). Skogstad's periodization of Canadian

\footnotetext{
${ }^{1}$ The agri-food sector includes the following activities: primary agriculture and related input and service suppliers, food beverage and tobacco processing, food retail and wholesale, and food service.
}

agri-food policy (Skogstad, 2008; Skogstad, 2011) highlights how increasing global competitiveness and export values has been a major policy pillar since the 1980s. Skogstad noted how agri-food policy underwent a shift from a "productivist" or "state assistance" paradigm (1945-1980s) to a "market liberal" paradigm (1980s-1990s). During the former, agri-food policy sought to improve conditions for the sector by encouraging increased production and by providing assistance through income support and domestic market protections. In contrast, the market liberal paradigm is shaped by neoliberal priorities, emphasizing global market competitiveness and reduced government intervention as the primary pathway to vitality in the agri-food system (Skogstad, 2012; Andrée et al., 2018). During this period, we see the embodiment of liberal market priorities within agri-food policy goals. In 1989, Agriculture Canada published a new vision for agri-food, Growing Together, which stressed the need to reduce reliance on government support, to develop and liberalize trade markets, and to eliminate market-distorting policies (Agriculture Canada, 1989; Skogstad, 2008). In 1993 and 1994, AAFC announced its overarching goals to reach minimum annual export values of $\$ 20$ billion and to capture 3.5\% of world trade by the year 2000 (Agriculture and Agri-food Canada, 1994). These policy targets were met. In 2001 Canadian agriculture and agri-food export values surpassed $\$ 25$ billion. Canada was the third largest exporter of agri-food products, representing $4.2 \%$ of the global share of agricultural exports (Agriculture and Agri-food Canada, 2003). Government policy orientations continue to target growth through export markets. The Federal government budget in 2017 flagged the agri-food sector as a key area for future economic growth and set the target of $\$ 75$ billion in annual exports by 2025 (Agriculture and Agrifood Canada, 2017). In Canada, as is likely the case in many other countries, the relationship between growth-focused policy and beneficial food system outcomes remains largely unquestioned and hence unexamined among agriculture and food policy efforts.

Skogstad (2012) notes that agri-food policy has incorporated more multifunctional goals since the year 2000. For example, high-level visions intended to guide agri-food policy have included some references to values such as environmental stewardship, rural community vitality, and food safety (Agriculture and Agri-food Canada, 2005; Agriculture and Agri-food Canada, 2008; Agriculture and Agri-food Canada, 2011). While Skogstad noted this shift, she questioned to what extent they are implemented and prioritized relative to neo-liberal goals of increasing production, export values and agricultural contributions to GDP.

The following section summarizes the primary critiques from Beyond GDP literature that advocate for alternative measures of policy success beyond economic growth. We illustrate these points with examples from the Canadian food system to highlight the connections between Beyond GDP research and food system policy.

\section{The Limitations of GDP for Measuring Wellbeing in the Food System Inclusion of all Monetary Goods and Services}

GDP measures the total monetary value of all final goods and services-regardless of whether these contribute to societal wellbeing. For example, healthcare expenditures, junk food sales, costs of pollution protection/remediation, and unjust 
labor practices may all contribute positively to GDP while adversely affecting societal wellbeing (Giannetti et al., 2015). For example, poor diet is a major risk factor for chronic diseases in Canada, including ischemic heart disease and type 2 diabetes (Institute for Health Metrics and Evaluation [IHME], 2010). The economic burden of diet-related health conditions has been estimated at $\$ 13$ billion CAD annually (Nshimyumukiza et al., 2018). As another example, fertilizer and other nutrient runoff from agriculture is a leading cause of freshwater eutrophication across Canada (Council of Canadian Academies [CCA], 2013; Liu et al., 2021). While national-level data on the cost of managing and remediating harmful algal blooms is limited (International Institute for Sustainable Development [IISD], 2017), governments in North America have reported spending tens of thousands to tens of millions of dollars in remediation efforts and increased operation and monitoring costs (Lyder et al., 2015; U.S. Evironmental Protection Agency, 2015). These cost are considered positive contributions to economic growth within GDP accounting frameworks.

\section{Obscured Growth Distribution and Societal Inequities}

Even in purely monetary terms, GDP's measure of value omits critical components of societal and economic wellbeing. GDP excludes indications of inequality, obscuring the relationship between increased economic activity at a national level, and increased economic wellbeing at the household level-i.e., who is benefitting from economic activity. For example, the number of Canadians with incomes below the "low-income cut-off" increased between 1980 and 2005, despite real GDP almost doubling over that same period (Victor, 2008; Washington, 2021). Juxtaposed, such conflicting indications of economic progress raise important concerns as to how a singular focus on growing the economy can advance overall societal wellbeing, and, by extension, the appropriateness of the widespread use of GDP in shaping and evaluating policy.

This dynamic is highlighted by examining net farmer incomes over the past few decades. While the sale values of farm commodities have increased in Canada since the 1970s, net farm income (excluding government subsidies) has declined and remained relatively depressed at levels that often cannot support farming businesses and families (Qualman, 2019). It's estimated that between 1985 and 2018, input costs accounted for more than 95\% of farm cash receipts (Qualman, 2019). This suggests that nearly all of the value generated by farmers during this period was redirected to other actors, including agribusiness input manufacturers and service providers such as seed, fertilizer, energy, or machinery companies, financial institutions etc. (Qualman et al., 2018). As such, focusing on the values of farm sales and contributions to GDP obscures the economic wellbeing of many farming families and communities.

Furthermore, many social, environmental, and economic determinants of wellbeing are structured around the outcomes of systemic racism and colonialism, yielding inequities that disproportionately disadvantage racialized communities (Public Health Agency of Canada [PHAC], 2018). For example, rates of household food insecurity in Canada are highest among Black and Indigenous households (Tarasuk and Mitchell, 2020). Household food insecurity is approximately two to four times as prevalent among Inuit, First Nations, and Métis households relative to non-Indigenous households (Public Health Agency of Canada, 2018) and Black Canadians reported experiencing moderate or severe food insecurity 2.8 times more frequently than White Canadians (Public Health Agency of Canada, 2020). These disparities are entirely obscured within attempts to measure societal wellbeing through GDP.

\section{Omission of Ecological Value}

Ecological integrity is excluded from GDP's accounting framework. Economic activities that deplete natural resources and/or accelerate climate change can all contribute positively to GDP, despite their capacity to degrade the ecosystems upon which societal wellbeing depends. Such omissions have engrained the prioritization of short-term monetary gains at the expense of long-term ecological stewardship, incentivizing the degradation of the ecological integrity required to support the wellbeing of future generations (Washington, 2021).

Kissinger and Rees (2009) highlighted how agricultural intensification for the purpose of meeting increasing export demand has degraded Canadian prairie ecosystems. This includes a near elimination of tall grass prairie ecosystems (Chliboyko, 2010), the draining of approximately 70\% of historic wetlands (Seburn and Seburn, 2000) and the loss of biodiversity dependent on these ecosystems. GDP accounting frameworks count the positive additions of increased export values while overlooking the impacts of habitat and biodiversity loss.

\section{Exclusion of Non-Market Services}

Household labour, parenting, volunteerism, and other activities integral to prosperous societies are not accounted for in GDP, as they are not monetized and exchanged for a price on the market (Mazzucato, 2018). The food system's essential purpose-feeding people-is largely overlooked in markets that prioritize monetary value. For example, climate change brings the potential for layered emergencies in the form of drought, wildfires, geopolitical instability, resource constraints, sea-level rise etc. (Intergovernmental Panel on Climate Change [IPCC], 2021). Stewarding regional food production capacity has been identified as a way to increase resilience during times of food system disruption (Dorward et al., 2017; Rees, 2019). However, this non-market value is overlooked as agricultural land is converted to more lucrative uses, eroding regional food production capacity and increasing local vulnerability to distant disruptions.

These omissions in the GDP accounting framework have significant implications for policy discussions. This is particularly true for the food system. For example, climate change economist, William Nordhaus (1991) argued that efforts to mitigate climate change should be limited in order to reduce adverse effects on economic growth. He proposed that, since agriculture and forestry, the two sectors most impacted by climate change, only contribute to $3 \%$ of the United States national output, the impacts of climate change on agriculture are of relatively little concern. Nordhaus proposed that the associated economic losses can be easily recovered with a few 
years of GDP growth-the majority of which results from sectors that are "negligibly affected by climate change" (William Nordhaus, 1991; Nordhaus and Boyer, 2000). Nordhaus' valuation of the food system based strictly on contributions to GDP has been strongly critiqued for overlooking the integral role of agricultural and natural systems in supporting human life (Daly, 2000; Erickson and Gowdy, 2002).

\section{Shifting From Agri-Food Policy to Coordinated Food System Policy}

As mentioned, agriculture has been the subject of the majority of food policy development in Canada, cited as its "primary driver" (MacRae, 2011). As such, food policy has largely overlooked many critical social and ecological dimensions of the food system. For example, there is relatively little public policy addressing food security and access (McIntyre et al., 2016; McIntyre et al., 2019) or the relationship between food environments and health (Vanderlee et al., 2019). In addition to producing policy gaps, siloed approaches to food policy development have been critiqued for delivering conflicting goals and problematic outcomes (MacRae, 2011). For example, local and provincial governments are increasing institutional local food procurement to bolster local economic development (Sinclair et al., 2014). However, international trade agreements are perceived as limiting the potential of these programs (Macrae, 2014; Grube-Cavers et al., 2018).

For more than three decades, scholars and grassroots movements have been advocating for more coordinated and comprehensive approaches to food policy development. (Koc et al., 2008; Andrée et al., 2018). Advocacy efforts have led to the adoption of Food Policy for Canada in 2019 (Agriculture and Agri-food Canada, 2019), the first national strategy encouraging policy development across previously siloed areas of the food system. This was accompanied by the creation of the Canadian Food Policy Advisory Council (Agriculture and Agri-food Canada, 2021) to inform ongoing federal policy efforts. While these advancements mark a notable step toward coordinated food system policy development, food policy advocates have responded that the policy falls short in key dimensions of wellbeing (Andree et al., 2021; Food Secure Canada [FSC], 2019; Macrae, 2019). Such outcomes however are not surprising if policy remains embedded in a larger growth-focused framework where GDP is a primary metric of success. The next section provides a brief overview of two areas of Beyond GDP research that, we believe, can offer helpful perspectives, language and models to advance more fundamental change in food system policy.

\section{Pathways for Beyond GDP Research to Inform Food System Policy Development Shifting Metrics: From GDP to Wellbeing and Sustainability}

A number of alternatives economic indicators have been developed in response to the limitations of GDP. For example, the United Nations Human Development Index (HDI), a composite indicator of GDP per capita, literacy and life expectancy, was developed to incorporate measures of development beyond economic activity. However, the indicator is critiqued for its omission of any measure of ecological sustainability (Morse, 2003). The Genuine Progress Indicator (GPI) (1997) adapts the GDP methodology, adding previously omitted elements (e.g., volunteerism) and subtracting contributions from activities seen to negatively impact wellbeing, such as crime and pollution (Giannetti et al., 2015). GPI studies have made important contributions by pointing to divergences between GDP and wellbeing (Kubiszewski et al., 2013). However the metric has been critiqued from both theoretical (Brennan, 2013) and methodological (Lawn, 2013) standpoints, particularly in how it omits an indication of sustainability. One often noted drawback to single, composite indicators is that they require an arbitrary weighting of their components, and the consequences of doing so are often obscured (Stiglitz et al., 2009). The landmark report by the Commission of the Measurement of Economic Performance and Social Progress (Stiglitz et al., 2009) recommended that a dashboard of indicators be used to measure societal wellbeing and underscored the need to assess the sustainability of current activities in addition to, and separately from, the level of wellbeing that they provide.

In Canada, alternative GDP indicator work has perhaps most notably taken the form of the Canadian Index of Wellbeing (CIW), a composite of 64 indicators across eight domains (Canadian Index of Wellbeing [CIW], 2011). Indicator reports have been updated periodically since its release in 2011 (Canadian Index of Wellbeing, 2016) as well as downscaled to provincial (Smale, 2019; Canadian Index of Wellbeing, 2014) and regional levels (Canadian Index of Wellbeing, 2018). Hayden and Wilson (2016) note that, despite the robust development process and continued work, there is no evident impact of the CIW on federal or provincial policy-making. They suggested that, while indicators are important tools for informing decision making, they are not in and of themselves agents of transformative change. In order to meaningfully impact policy, indicators must be embedded within decision-making paradigms that prioritize their value.

\section{Shifting Frameworks: From Exponential Growth to Ecological Boundaries}

A movement of scholars and activists are calling for a more fundamental paradigm shift to adequately address the social, economic and ecological concerns stemming from the growthfocused policy development of the 20th century. Examples include steady-state economics (Daly, 1991; Washington and Twomey, 2016), the de-growth movement (Martínez-Alier et al., 2010), and Doughnut Economics (Dearing et al., 2014; Raworth, 2017), to name a few. While exploring the origins, ideological overlaps and divergences between these paradigms is beyond the scope of this mini-review (see Martínez-Alier et al., 2010; Washington and Maloney, 2020), they all have an important common foundation: sustainability requires that human activities be bounded by the capacity of the ecosystems to regenerate and absorb (Daly and Farley, 2010) and society 
cannot sustain infinite growth on a finite planet. This research argues that our pathways for "success" must therefore shift away from increasing material wealth through exponential growth, and toward providing for healthy, dignified lives within ecosystem capacity. This more fundamental paradigm shift has important alignment with calls for food system policy reform to deliver better outcomes for societal wellbeing.

\section{CONCLUSION AND FUTURE RESEARCH}

Despite their alignment, policy reforms within the food system literature are rarely framed explicitly in the context of Beyond GDP literature. This review suggests that Beyond GDP research can provide powerful perspectives, language and models to help advance the fundamental reforms frequently called for by proponents of food system policy change. Reciprocally, the food system presents a unique opportunity to explore ecological economic models and applications. We offer that strengthening connections between the two areas of rich and established research can therefore be mutually beneficial and highlight the following questions. What alternative metrics to GDP can inform food policy development that centers societal wellbeing? What alternatives to growth-focused economic

\section{REFERENCES}

Agriculture and Agri-food Canada. (2005). Agricultural Policy Framework. Agriculture and Agri-food Canada. (2003). An Overview of the Canadian Agriculture and Agri-Food System.

Agriculture and Agri-food Canada. (2017). Budget 2017 Supports Canada's Agriculture and Agri-Food Sector as an Important Driver of Economic Growth. Available at: https://agriculture.canada.ca/en/agri-info/budget-2017supports-canadas-agriculture-and-agri-food-sector-important-drivereconomic-growth.

Agriculture and Agri-food Canada (2019). Food Policy for Canada: Everyone at the Table. Available at: https://agriculture.canada.ca/sites/default/files/legacy/pack/ pdf/fpc_20190614-en.pdf.

Agriculture and Agri-food Canada. (1994). Future Directions for Canadian Agriculture and Agri-Food. Requested Form Agriculture and Agri-Food Canada.

Agriculture and Agri-food Canada. (2008). Growing Forward: A Federal Provincial - Territorial Framework Agreement on Agriculture, Agri-Food and Agri-Based Products Policy.

Agriculture and Agri-food Canada. (2011). Saint Andrews Statement.

Agriculture and Agri-food Canada. (2021). The Canadian Food Policy Advisory Council. Retrieved from https://agriculture.canada.ca/en/about-ourdepartment/key-departmental-initiatives/food-policy/canadian-food-policyadvisory-council. December 1, 2021

Agriculture Canada. (1989). Growing Together. Requested from Agriculture and Agri-food Canada. Canada, October, 2021.

Andree, P., Ballamingie, P., and Coulas, M. (2021). Integrative Governance for Ecological Public Health: An Analysis of 'Food Policy for Canada' (2015-2019). CanFoodStudies 8 (2), 189-226. doi:10.15353/cfs-rcea.v8i2.450

Andrée, P., Coulas, M., and Ballamingie, P. (2018). Governance Recommendations from Forty Years of National Food Strategy Development in Canada and beyond. CanFoodStudies 5, 6-27. doi:10.15353/cfs-rcea.v5i3.283

Brennan, A. J. (2013). A Critique of the Perceived Solid Conceptual Foundations of ISEW \& GPI - Irving Fisher's Cognisance of HumanHealth Capital in 'net Psychic Income'. Ecol. Econ. 88, 159-166. doi:10.1016/j.ecolecon.2012.12.026 models can guide the food system to support wellbeing across ecological, economic and social dimensions? And, importantly, how can we address the barriers, including governance structures, political forces, knowledge gaps, and vested interests, that prevent transformative paradigm change? We offer these questions to guide future research at the intersection of ecological economics and food systems policy.

\section{AUTHOR CONTRIBUTIONS}

NR was the primary author, developing the concept for the paper, completing the literature review, synthesizing key concepts, writing the draft and attending to the revisions. KM reviewed and edited the article and provided intellectual guidance for its conceptual development. Both authors reviewed and approved the final version of the article for publication.

\section{FUNDING}

This research is supported by the Social Science and Humanities Research Council (SSHRC), College and Community Social Innovation Fund (CCSIF). SSHRC reference: 970-2021-1015.

Canadian Indeox of Wellbeing (2014). How Are Ontarians Really Doing ? A Provincial Report on Ontario Wellbeing. Available at: https://uwaterloo.ca/ canadian-index-wellbeing/reports.

Canadian Index of Wellbeing (2018). A Profile of Wellbeing in Waterloo Region. January, 1-55. Available at: https://uwaterloo.ca/canadian-index-wellbeing/ reports.

Canadian Index of Wellbeing. (2011). How Are Canadians Really Doing? Highlights: Canadian Index of Wellbeing 1.0.

Canadian Index of Wellbeing (2016). How Are Canadians Really Doing? the 2016 CIW National Report. 1-82. Available at: https://uwaterloo.ca/canadian-indexwellbeing/reports.

Chliboyko, J. (2010). A Prairie Still Standing Tall, Barely. Canadian National Geographic. Available at: http://www.canadiangeographic.ca/article/prairiestill-standing-tall-barely.

Common, M., and Boyer, J. (2002). William D. Nordhaus and Joseph Boyer, Warming the World: Economic Models of Global Warming. MIT Press, Cambridge Mass., 2000. ISBN 026214071 3. Envir. Dev. Econ. 7, 593-601. doi:10.1017/S1355770X02240346

Costanza, R. (2008). Ecological Economics 1. Editors S. E. Jørgensen, (Cambridge, Massachusetts, United States: Academic Press), 999-1006. doi:10.1016/B978008045405-4.00619-4

Costanza, R., Hart, M., Posner, S., and Talberth, J. (2009). Beyond GDP : The Need for New Measures of Progress beyond. Boston Univ. 4, 1-47.

Council of Canadian Academies [CCA] (2013). Water and Agriculture in Canada: Towards Sustainable Management of Water Resources. Available at: https://ccareports.ca/reports/water-and-agriculture-in-canada-towards-sustainablemanagement-of-water-resources/.

Daly, H. E., and Farley, J. C. (2010). Ecological Economics: Principles and Applications. 2nd ed. Washington, D.C.: Island Press.

Daly, H. E. (1991). Steady-state Economics. 2nd ed. Washington, D.C.: Island Press.

Daly, H. E. (2000). When Smart People Make Dumb Mistakes. Ecol. Econ. 34 (1), 1-2. doi:10.1016/S0921-8009(00)00174-9

Dearing, J. A., Wang, R., Zhang, K., Dyke, J. G., Haberl, H., Hossain, M. S., et al. (2014). Safe and Just Operating Spaces for Regional Social-Ecological Systems. Glob. Environ. Change 28, 227-238. doi:10.1016/ j.gloenvcha.2014.06.012 
Dietz, R., and O’Neill, D. (2013). Enough Is Enough: Building a Sustainable Economy in a World of Finite Resources. Oakland, CA: Berrett-Koehler Publishers.

Dorward, C., Smukler, S. M., and Mullinix, K. (2017). A Novel Methodology to Assess Land-Based Food Self-reliance in the Southwest British Columbia Bioregion. Renew. Agric. Food Syst., 32(2), 112-130. doi:10.1017/S1742170516000053

Erickson, J. D., and Gowdy, J. M. (2002). The Strange Economics of Sustainability. BioScience 52 (3), 212. doi:10.1641/0006-3568(2002)052

Fioramonti, L. (2013). Gross Domestic Problem : The Politics behind the World's Most Powerful Number. London, United Kingdom: Bloomsbury Publishing.

Food Secure Canada [FSC]. (2017). From Patchwork to Policy Coherence: Principles and Priorities of Canada 's National Food Policy (Issue May).

Food Secure Canada [FSC] (2015). Resetting the Table: A People's Food Policy for Canada. Available at: https://foodsecurecanada.org/people-food-policy.

Food Secure Canada [FSC] (2019). The Launch of the First 'Food Policy for Canada - Everyone at the Table. Available at: https://foodsecurecanada.org/ first-national-food-policy-for-canada\#analysis.

Giannetti, B. F., Agostinho, F., Almeida, C. M. V. B., and Huisingh, D. (2015). A Review of Limitations of GDP and Alternative Indices to Monitor Human Wellbeing and to Manage Eco-System Functionality. J. Clean. Prod. 87, 11-25. doi:10.1016/j.jclepro.2014.10.051

Grube-Cavers, A., Tatebe, K., Polasub, W., Augustinowicz, G., and Mullinix, K. (2018). Okanagan Bioregion Institutional Procurement Study. Surrey, Canada: Kwantlen Polytechnic University.

Hayden, A., and Wilson, J. (2016). Is it what You Measure that Really Matters? the Struggle to Move beyond GDP in Canada. Sustainability 8 (7), 623. doi:10.3390/ su8070623

Intergovernmental Panel on Climate Change [IPCC] (2021). "Summary for Policymakers," in Climate Change 2021: The Physical Science Basis. Contribution of Working. Energy and Environment. Editors Masson-, M. V. Delmotte, P. Zhai, A. Pirani, S. L. Connors, C. Péan, et al.doi:10.1260/095830507781076194

Institute for Health Metrics and Evaluation [IHME]. (2010). GBD Profile Canada. Institute for Health Metrics and Evaluation. (Seattle, WA). Available at: https:// www.healthdata.org/sites/default/files/files/country_profiles/GBD/ihme_gbd_ country_report_canada.pdf.

International Institute for Sustainable Development [IISD] (2017). Costs of Pollution in Canada. Available at: https://www.iisd.org/publications/costspollution-canada-measuring-impacts-families-businesses-and-governments.

Kissinger, M., and Rees, W. E. (2009). Footprints on the Prairies: Degradation and Sustainability of Canadian Agricultural Land in a Globalizing World. Ecol. Econ. 68 (8), 2309-2315. doi:10.1016/j.ecolecon.2009.02.022

Koc, M., MacRae, R., Desjardins, E., and Roberts, W. (2008). Getting Civil about Food: The Interactions between Civil Society and the State to Advance Sustainable Food Systems in Canada. J. Hunger Environ. Nutr. 3 (2-3), 122-144. doi:10.1080/19320240802243175

Kubiszewski, I., Costanza, R., Franco, C., Lawn, P., Talberth, J., Jackson, T., et al. (2013). Beyond GDP: Measuring and Achieving Global Genuine Progress. Ecol. Econ. 93, 57-68. doi:10.1016/j.ecolecon.2013.04.019

Lawn, P. (2013). The Failure of the ISEW and GPI to Fully Account for Changes in Human-Health Capital - A Methodological Shortcoming Not a Theoretical Weakness. Ecol. Econ. 88, 167-177. doi:10.1016/j.ecolecon.2012.12.028

Levkoe, C., Levebvre, R., and Palmer, A. B. (2017). Food Counts: A Pan-Canadian Sustainable Food Systems Report Card. Available at: https://fledgeresearch.ca/ wp-content/uploads/2017/05/food-counts-pan-canadian-sustainable-food-systemsreport-card2.pdf.

Liu, J., Elliott, J. A., Wilson, H. F., Macrae, M. L., Baulch, H. M., and Lobb, D. A. (2021). Phosphorus Runoff from Canadian Agricultural Land: A Cross-Region Synthesis of Edge-Of-Field Results. Agric. Water Manag. 255. 107030. doi:10.1016/j.agwat.2021.107030

Lyder, R., Gray, E., and Sandborn, C. (2015). Cleaning up Elk and Beaver Lakes : What Can Be Learned from Other Lakes. Available at: http://www.elc.uvic.ca/ wordpress/wp-content/uploads/2016/04/CleaningUpElkandBeaverLakes.pdf.

MacRae, R. (2011). A Joined-Up Food Policy for Canada. J. Hunger Environ. Nutr. 6 (4), 424-457. doi:10.1080/19320248.2011.627297

Macrae, R. (2014). Do trade Agreements Substantially Limit Development of Local/ Sustainable Food Systems in Canada? CanFoodStudies 1 (1), 103-125. doi:10.15353/cfs-rcea.vli1.25
MacRae, R. (1999). "Policy Failure in the Canadian Food System", in For HungerProof Cities: Sustainable Urban Food Systems. Editor M. Koc (Kent St, Ottawa: International Development Research Centre), 182-194.

Macrae, R. (2019). Two Pieces Added to National Food Policy: many Parts Still Missing. Available at: https://foodpolicyforcanada.info.yorku.ca/2019/06/twopieces-added-to-national-food-policy-many-parts-still-missing/.

Martínez-Alier, J., Pascual, U., Vivien, F.-D., and Zaccai, E. (2010). Sustainable Degrowth: Mapping the Context, Criticisms and Future Prospects of an Emergent Paradigm. Ecol. Econ. 69 (9), 1741-1747. doi:10.1016/j.ecolecon.2010.04.017 Mazzucato, M. (2018). The Value of Everything. Hachette UK.

McIntyre, L., Patterson, P. B., Anderson, L. C., and Mah, C. L. (2016) Household Food Insecurity in Canada: Problem Definition and Potential Solutions in the Public Policy Domain. Can. Public Pol. 42 (1), 83-93. doi:10.3138/cpp.2015-066

McIntyre, L., Patterson, P. B., and Mah, C. L. (2019). The Application of 'valence' to the Idea of Household Food Insecurity in Canada. Soc. Sci. Med. 220, 176-183. doi:10.1016/j.socscimed.2018.11.016

Morse, S. (2003). Greening the United Nations' Human Development Index? Sust. Dev. 11 (4), 183-198. doi:10.1002/sd.219

Nordhaus, W. D. (1991). To Slow or Not to Slow: The Economics of the Greenhouse Effect. Econ. J. 101 (407), 920-937. doi:10.2307/2233864

Nshimyumukiza, L., Lieffers, J. R. L., Ekwaru, J. P., Ohinmaa, A., and Veugelers, P. J. (2018). Temporal Changes in Diet Quality and the Associated Economic burden in Canada. PLoS One 13 (11). e0206877 doi:10.1371/ journal.pone.0206877

Podlasly, M., Von Der Porton, S., Kelly, D., Kelly, D., and Lindley-Peart, M. (2020). Centering First Nations Concepts of Wellbeing: Toward a GDP-Alternative Index in British Columbia. Available at: https://www.bcafn.ca/sites/default/files/docs/ reports-presentations/BC\%20AFN\%20FINAL\%20PRINT\%202020-11-23.pdf.

Public Health Agency of Canada (2018). Key Health Inequalities in Canada: A National Portrait. Available at: https://www.canada.ca/en/public-health/ services/publications/science-research-data/inequalities-food-insecuritycanada-infographic.html.

Public Health Agency of Canada (2020). Social Determinants and Inequities in Health for Black Canadians: A Snapshot. Available at: https://www.canada.ca/ en/public-health/services/health-promotion/population-health/whatdetermines-health/social-determinants-inequities-black-canadians-snapshot.html.

Qualman, D., Akram-Lodhi, A. H., Desmarais, A. A., and Srinivasan, S. (2018). Forever Young? the Crisis of Generational Renewal on Canada's Farms. Canadaian Food Stud. 5 (3), 11-127. doi:10.15353/cfs-rcea.v5i3.284

Qualman, D. (2019). Tackling the Farm Crisis and the Climate Crisis. Available at: https://www.nfu.ca/wp-content/uploads/2020/01/Tackling-the-Farm-Crisisand-the-Climate-Crisis-NFU-2019.pdf.

Raworth, K. (2017). Doughnut Economics: Seven Ways to Think like a 21st century Economist. White River Junction, Hartford, Vermont, United States: Chelsea Green Publishing.

Rees, W. (2019). Why Place-Based Food Systems? Food Security in a Chaotic World. J. Agric. Food Syst. Community Dev. 9 (A), 1-9. doi:10.5304/ jafscd.2019.091.014

Seburn, D., and Seburn, C. (2000). Conservation Priorities for the Amphibians and Reptiles of Canada Prepared for World Wildife Fund Canada and Canadian Amphibian and Reptile Conservation Network. Toronto, Canada: WWF Canada.

Sinclair, S., Trew, S., and Mertins-Kirkwood, H. (2014). Making Sense of the CETA. Report for the Canadian Centre for Policy Alternatives Available at: https:// www.policyalternatives.ca/publications/reports/making-sense-ceta.

Skogstad, G. (2011). An Overview of Policy Goals, Objectives, and Instruments for the Agri-Food Sector. Available at: https://capi-icpa.ca/wp-content/uploads/ 2011/02/An-Overview-of-Policy-Goals-Objectives-and-Instruments-in-theAgri-Food-Sector-2011.pdf.

Skogstad, G. (2008). Canadian Agricultural Programs and Paradigms:The Influence of International Trade Agreements and Domestic Factors. Can. J. Agric. Economics/Revue Canadienne d'agroeconomie 56 (4), 493-507. doi:10.1111/j.1744-7976.2008.00143.x

Skogstad, G. (2012). "Effecting Paradigm Change in the Canadian Agriculture and Food Sector," in Health and Sustainability in the Canadian Food System: Advocacy and Opportunity for Civil Society. Editors E. A. Abergel and R. John MacRae (Vancouver, Canada: UBC Press). 
Smale, B. (2019). How are Residents of Saskatchewan Really Doing ? A Report by the Canadian Index of Wellbeing prepared for Heritage Saskatchewan and the Community Initiatives Fund (Issue October).

Stiglitz, J. E. (2020). GDP Is the Wrong Tool for Measuring what Matters. Basingstoke, United Kingdom: Scientific American. Available at: https:// www.scientificamerican.com/article/gdp-is-the-wrong-tool-for-measuringwhat-matters/.

Stiglitz, J. E., Sen, A., and Fitoussi, J.-P. (2010). Mismeasuring Our Lives Why GDP Doesn't Add up. New York, New York, United States: The New Press.

Stiglitz, J., Sen, A., and Fitoussi, J.-P. (2009). Report by the Commission on the Measurement of Economic Performance and Social Progress.

Tarasuk, V., and Mitchell, A. (2020). Household Food Insecurity in Canada, 2017-2018.

U.S. Evironmental Protection Agency (2015). A Compilation of Cost Data Associated with the Impacts and Control of Nutrient Pollution. Available at: https://www.epa.gov/sites/default/files/2015-04/documents/nutrienteconomics-report-2015.pdf.

Vanderlee, L., Goorang, S., Karbasy, K., Vandevijvere, S., and L'Abbé, M. R. (2019). Policies to Create Healthier Food Environments in Canada: Experts' Evaluation and Prioritized Actions Using the Healthy Food Environment Policy Index (Food-EPI). Ijerph 16 (22), 1-17. doi:10.3390/ijerph16224473

Victor, P. A. (2008). Managing without Growth: Slower by Design, Not Disaster. Cheltenham, United Kingdom: Edward Elgar.
Washington, H., and Maloney, M. (2020). The Need for Ecological Ethics in a New Ecological Economics. Ecol. Econ. 169. 106478 doi:10.1016/j.ecolecon.2019.106478 Washington, H. (2021). Questioning the Assumptions, Sustainability and Ethics of Endless Economic Growth. Jrfm 14 (10), 497. doi:10.3390/jrfm14100497

Washington, H., and Twomey, P. (2016). A Future beyond Growth towards a Steady State Economy. 1st ed.. Milton Park, Abingdon-on-Thames, Oxfordshire, England, UK: Routledge.

Conflict of Interest: The authors declare that the research was conducted in the absence of any commercial or financial relationships that could be construed as a potential conflict of interest.

Publisher's Note: All claims expressed in this article are solely those of the authors and do not necessarily represent those of their affiliated organizations, or those of the publisher, the editors and the reviewers. Any product that may be evaluated in this article, or claim that may be made by its manufacturer, is not guaranteed or endorsed by the publisher.

Copyright (c) 2022 Robert and Mullinix. This is an open-access article distributed under the terms of the Creative Commons Attribution License (CC BY). The use, distribution or reproduction in other forums is permitted, provided the original author(s) and the copyright owner(s) are credited and that the original publication in this journal is cited, in accordance with accepted academic practice. No use, distribution or reproduction is permitted which does not comply with these terms. 